\title{
Dysplastic Nevus Syndrome
}

National Cancer Institute

\section{Source}

National Cancer Institute. Dysplastic Nevus Syndrome. NCI Thesaurus. Code C7584.

An autosomal dominant disorder defined by the presence of multiple dysplastic nevi and a history of melanoma in two family members. Patients are at an increased risk for the development of melanoma. 